\title{
Description and phylogenetic position of a new species of Rhabdias Stiles et Hassall, 1905 (Nematoda: Rhabdiasidae) from the banded rubber frog, Phrynomantis bifasciatus (Smith) (Amphibia: Microhylidae), in South Africa
}

\author{
Yuriy Kuzmin ${ }^{1}$, Ali Halajian ${ }^{2}$, Sareh Tavakol ${ }^{2}$, Wilmien J. Luus-Powell ${ }^{2}$ and Vasyl V. Tkach ${ }^{3}$ \\ ${ }^{1}$ Department of Parasitology, I. I. Schmalhausen Institute of Zoology, Kyiv, Ukraine; \\ ${ }^{2}$ Department of Biodiversity (Zoology), University of Limpopo, Sovenga, South Africa; \\ ${ }^{3}$ Department of Biology, University of North Dakota, Grand Forks, ND, USA
}

\begin{abstract}
The lung-dwelling nematode Rhabdias engelbrechti sp. n. was found in five of eight examined banded rubber frogs in Limpopo Province, South Africa. The species is differentiated from species of Rhabdias Stiles et Hassall, 1905 occurring in the Afrotropical Realm based on the presence of a globular cuticular inflation at the anterior end, the buccal capsule walls being distinctly divided into anterior and posterior parts, the buccal capsule size $(6-9 \mu \mathrm{m} \times 16-18 \mu \mathrm{m})$, and the body length $(3.8-6.1 \mathrm{~mm})$. Rhabdias engelbrechti is the tenth species of the genus found in Afrotropical anurans. Our molecular phylogenetic analysis based on the complete sequences of the ITS region and partial sequences of large subunit (28S) gene of the nuclear ribosomal RNA demonstrates that the new species is more closely related to the Eurasian species Rhabdias bufonis (Schrank, 1788) than to two other species from sub-Saharan Africa represented in the tree. In addition, partial sequences of the mitochondrial protein coding coxl and ribosomal $12 \mathrm{~S}$ genes of the new species have shown significant differences from all previously published sequences of these genes from African species of Rhabdias.
\end{abstract}

Keywords: Rhabdias engelbrechti sp. n., amphibians, Limpopo Province, morphology, molecular phylogeny, rDNA, cox 1

Rhabdias Stiles et Hassall, 1905 is the largest genus of the Rhabdiasidae Railliet, 1915 comprising about 80 nominal species (Kuzmin and Tkach 2017) of lung-dwelling parasites of amphibians and reptiles. Species of the genus are known from all zoogeographical realms, except Antarctica. Currently, 23 species of the genus have been reported from the Afrotropical realm, ten of them as parasites in amphibians. Of these, Rhabdias bdellophis Baylis, 1929 is the only parasite of caecilians (Gymnophiona) (Baylis 1929), while the remaining nine species parasitise hosts of the order Anura.

Three species, R. blommersiae Kuzmin, Junker, du Preez et Bain, 2013, R. madagascariensis Chabaud, Brygoo et Petter, 1961 and $R$. vencesi Junker, Lhermitte-Vallarino et Bain, 2010, are distributed on Madagascar. The six remaining species, $R$. africanus Kuzmin, 2001, R. collaris Baker, 1987, R. ohlerae Junker, Lhermitte-Vallarino et Bain, 2010, R. picardiae Junker, Lhermitte-Vallarino et Bain, 2010, R. sylvestris (Baker, 1982) and R. tanyai Junker, Lhermitte-Vallarino et Bain, 2010 occur on mainland sub-Saharan Africa, parasitising hosts of the families Ar- throleptidae, Bufonidae and Microhylidae (Chabaud et al. 1961, Baker 1982, 1987, Kuzmin 2001, Junker et al. 2010, Kuzmin et al. 2013, Tkach et al. 2014a).

In the present paper we describe a new species of Rhabdias collected from the banded rubber frog, Phrynomantis bifasciatus (Smith) (Microhylidae), in Limpopo Province, South Africa. Morphological and molecular differentiation (based on cytochrome oxidase 1 (coxl) and $12 \mathrm{~S}$ mitochondrial genes) of the new species from previously described African species of Rhabdias parasitic in anurans is provided along with an analysis of its phylogenetic position based on sequences of the complete ITS region and partial 28S gene of nuclear ribosomal DNA.

\section{MATERIALS AND METHODS}

Eight banded rubber frogs were found dead in January 2013 on the farm De Loskop $\left(23^{\circ} 30^{\prime} \mathrm{S} ; 2^{\circ} 18^{\prime} \mathrm{E}\right)$ in the vicinity of Polokwane, Limpopo Province, South Africa (permit number 001-CPM403-00012 from the Limpopo Department of Economic Development, Environment \& Tourism). Collected frogs were transferred on ice to the Laboratory of Parasitology, University of

Address for correspondence: V.V. Tkach, Department of Biology, University of North Dakota, 10 Cornell Street, Grand Forks, ND 58202, USA. Phone: 1-701-777-4675; E-mail: vasyl.tkach@und.edu

Zoobank number for article: urn:lsid:zoobank.org:pub:2D3F9905-F70E-4B46-9479-3E1066A3F7DA 
Limpopo and examined for parasites. The frogs had a weight of 4.7-7.9 $\mathrm{g}$ (average $6.4 \mathrm{~g}$ ) and a snout to vent length of 4.0-4.7 cm (average $4.5 \mathrm{~cm}$ ). All frogs had cestodes in their intestine, seven harboured nematodes in the large intestine and five of them also had rhabdiasid nematodes in their lungs. Prior to examination under a light microscope, the nematodes were cleared in lactophenol (mixture of equal parts of distilled water, phenol, glycerol and lactic acid). Cleared specimens were studied on temporary slides under a Zeiss Axio Imager M1 microscope equipped with differential interference contrast optics and digital imaging system. Apical sections were made manually and examined en face. Drawings were made from series of photomicrographs. Measurements were taken with the use of the digital imaging system. Measurements of 20 specimens from three frogs are given in Table 1. All measurements are in micrometres unless otherwise indicated.

Genomic DNA of one individual of the new species as well as a specimen of another species from sub-Saharan Africa, $R$. africanus (collected from Sclerophrys gutturalis [Power, 1927] and kindly provided by Odile Bain and Kerstin Junker) was extracted according to Tkach and Pawlowski (1999). Fragments of the nuclear DNA region spanning the $3^{\prime}$ end of the $18 \mathrm{~S}$ nuclear rRNA gene, ITS region (ITS1+5.8S+ITS2) and 5' end of the 28S gene (including variable domains D1-D3) were amplified by PCR on an Eppendorf Master Gradient thermal cycler (Hauppauge, NY, USA), using forward primer ritf (5'-GCG GCT TAA TTT GAC TCA ACA CGG-3'), and reverse primer 1500R (5'GCT ATC CTG AGG GAA ACT TCG-3'). PCR reactions were performed using New England Biolabs ${ }^{\circledR}$ (Ipswich, MA, USA) OneTaq ${ }^{\circledR}$ Quick-Load ${ }^{\circledR}$ Master Mix according to manufacturer's instructions. Annealing temperature in these PCR reactions was $53^{\circ} \mathrm{C}$. PCR product was purified using Qiagen Qiaquick $^{\mathrm{TM}}$ (Valencia, CA, USA) columns and sequenced directly on an ABI Prism $3100^{\mathrm{TM}}$ (Carlsbad, CA, USA) automated capillary sequencer using ABI BigDye ${ }^{\mathrm{TM}}$ chemistry according to manufacturer's protocols. DNA product was sequenced in both directions using the two PCR primers and, additionally, internal primers ITS4 (5'-TCC TCC GCT TAT TGA TAT GC-3'), 300R (5'-CAA CTT TCC CTC ACG GTA CTT G-3'), 300F (5'-CAA GTA CCG TGA GGG AAA GTT G-3') and ECD2 (5'-CTT GGT CCG TGT TTC AAG ACG GG$\left.3^{\prime}\right)$. Considering that most of the Afrotropical species of Rhabdias are represented in GenBank by partial sequences of mitochondrial cox 1 and ribosomal 12S genes (Junker et al. 2010), we have sequenced these genes from both the new species and $R$. africanus. Coxl amplicons were obtained using primers LCO1490 (5'-GGTCAACAAATCATAAAGATATTGG-3') and HCO2198 (5'-TAAACTTCAGGGTGACCAAAAAATCA-3') published by Casiraghi et al. (2004). Partial 12S gene amplicons were obtained using primers 12SF (5'-GTTCCAGAATAATCGGCT A-3') and 12SR (5'-ATTGACGGATG(AG)TTTGTACC-3') published by Casiraghi et al. (2004). An annealing temperature of $45^{\circ} \mathrm{C}$ was used in both cases. PCR primers were used as sequencing primers for both mitochondrial genes.

Contiguous sequences were assembled and edited using Sequencher ${ }^{\mathrm{TM}}$ ver. 4.1.1 (GeneCodes Corp., Ann Arbor, MI, USA) and deposited in GenBank under accession numbers MG428406, MG428408, MG428410 (R. engelbrechti sp. n.) and MG428407, MG428409, MG428411 ( $R$. africanus). The phylogenetic analysis included newly obtained nuclear ribosomal sequences of $R$. engelbrechti and $R$. africanus and previously published (Tkach et al. 2006, 2014a,b) sequences of 16 additional species of Rhabdias from different continents and host groups. Pneumonema tiliquae Johnston, 1916 was chosen as outgroup based on the results of the phylogenetic analysis of the Rhabdiasidae by Tkach et al. (2014b). Names of the taxa and GenBank numbers are presented in Tables 2 and 3.

The new sequences and sequences obtained from GenBank were initially aligned using MEGA6 software (Tamura et al. 2013). The alignments were then manually refined in MEGA6 and saved in FASTA format. NEXUS file for Bayesian analysis was prepared in text editor. The phylogenetic analysis was carried out using Bayesian inference as implemented in the MrBayes program, version 2.01 (Huelsenbeck et al. 2001) with the following nucleotide substitution parameters: 1 set $n s t=6$, rates=invgamma, ncat $=4$, shape $=$ estimate, inferrates $=$ yes and basefreq $=$ empirical, that correspond to a general time reversible (GTR) model including estimates of the proportion of invariant sites (I) and gamma (G) distributed among-site rate variation.

The substitution model was selected using Jmodeltest ver. 0.1.1 (Posada 2008) software. Posterior probabilities were approximated over 3,000,000 generations, log-likelihood scores plotted and only the final $50 \%$ of trees were used to produce the consensus trees by setting the 'burnin' parameter at 750,000 generations. The resulting phylogenetic trees were visualised using FigTree ver. 1.4 software (Rambaut 2012).

Newly obtained mitochondrial sequences from the new species $R$. engelbrechti and $R$. africanus were compared with compatible sequences of species of Rhabdias published by Junker et al. (2010). In the publication by Junker at al. (2010) the GenBank accession numbers for sequences of $R$. tanyai were provided incorrectly and duplicated those of $R$. vencesi. In the present work we use corrected GenBank numbers for sequences of $R$. tanyai. Pairwise nucleotide comparison data and genetic identity matrices for $\operatorname{cox} 1$ and $12 \mathrm{~S}$ sequences were generated using MEGA6 software.

\section{RESULTS}

\section{Rhabdias engelbrechti sp. n.}

Figs. 1, 2

ZooBank number for species:

urn:1sid:zoobank.org:act:9636FB19-DFC7-4872-88C4-EF910925AC78

Description (based on the holotype and 4 paratypes, all gravid hermaphrodites; measurements of the holotype are followed by the ranges for the type series in parentheses. Measurements of all studied specimens are given in Table 1). Body length $5.06 \mathrm{~mm}$ (4.70-5.49 mm). Body 362 (306-362) wide at mid-body, gradually tapering anteriorly and posteriorly (Fig. 2A). Body width 156 (127-156) at junction of oesophagus and intestine, 145 (119-145) at anus. Anterior end rounded, posterior end tapered. Body cuticle more prominently inflated in anterior and posterior thirds of body, thin at mid-region. Spherical cuticular inflation (cephalic vesicle) present on anterior extremity, more or less distinctly separated from cuticle of remainder of body (Figs. 1A,C, 2B). Slight dilatation of body wall inside cephalic vesicle present at level of anterior end of 
Table 1. Measurements of Rhabdias engelbrechti sp. n. from Phrynomantis bifasciatus (Smith), all measurements are in micrometres unless otherwise indicated.

\begin{tabular}{|c|c|c|c|c|c|}
\hline Characters & Mean & Min. & Max. & SD & $\mathrm{CV}$ \\
\hline Body length (mm) & 4.9 & 3.8 & 6.1 & 0.5 & 10.1 \\
\hline Body width at oesophago-intestinal junction & 146 & 111 & 158 & 11.6 & 8.0 \\
\hline Body width at vulva & 316 & 218 & 362 & 28.8 & 9.1 \\
\hline Body width at anus & 119 & 73 & 145 & 14.6 & 12.3 \\
\hline Buccal capsule width & 17 & 16 & 18 & 0.8 & 4.6 \\
\hline Length of buccal capsule anterior part & 5.3 & 4 & 7 & 0.7 & 12.5 \\
\hline Length of buccal capsule posterior part & 2.5 & 2 & 3 & 0.5 & 20.5 \\
\hline Total length of buccal capsule & 7.8 & 6 & 9 & 0.9 & 11.1 \\
\hline Vestibulum length & 4.2 & 3 & 5 & 0.7 & 17.0 \\
\hline Oesophagus length & 361 & 293 & 393 & 25.8 & 7.1 \\
\hline Oesophagus width at anterior end & 34 & 32 & 37 & 1.4 & 4.2 \\
\hline Oesophagus width at muscular part & 38 & 33 & 42 & 2.8 & 7.2 \\
\hline Oesophagus width at nerve ring & 35 & 27 & 40 & 2.7 & 7.6 \\
\hline Oesophagus, bulb width & 61 & 53 & 64 & 2.5 & 4.2 \\
\hline Distance from anterior end to nerve ring & 158 & 138 & 171 & 9.2 & 5.8 \\
\hline Distance from anterior end to vulva (mm) & 2.6 & 2.1 & 3.1 & 0.28 & 10.7 \\
\hline Tail length & 253 & 166 & 317 & 34.5 & 13.6 \\
\hline \multicolumn{6}{|l|}{ Ratios } \\
\hline Oesophagus length/total body length (\%) & 7.4 & 6.0 & 8.3 & 0.6 & 7.9 \\
\hline Distance to vulva/total body length (\%) & 53.2 & 48.0 & 58.4 & 2.4 & 4.5 \\
\hline Tail length/total body length (\%) & 5.2 & 3.7 & 6.2 & 0.6 & 12.1 \\
\hline Distance from anterior end to nerve ring, in $\%$ of oesophagus length & 43.8 & 39.9 & 53.2 & 3.7 & 8.4 \\
\hline Buccal capsule length/width & 0.5 & 0.4 & 0.5 & 0.05 & 10.5 \\
\hline
\end{tabular}

$\mathrm{n}=20 ; \mathrm{SD}$ - standard deviation; $\mathrm{CV}$ - coefficient of variation.

oesophagus (Fig. 1A,B). Lateral cuticular pores extending along body.

Oral opening rounded (Fig. 1B). Internal labial papillae minute. Submedian papillae located close to edge of oral opening, lateral papillae at some distance from oral opening. Lips small, in shape of low apical elevations around and posterior to papillae (Fig. 1B). Amphids open as pores just posterior to lateral lips (Fig. 1B).

Vestibulum narrowing at its mid-length (Fig. 1C), 5 (4-5) long, circular in apical view (Fig. 1D). Buccal capsule 17 (17-18) wide, 8 (8-9) long, consisting of thickwalled barrel-shaped anterior part 5 (5-6) long and ringshaped posterior part 3 long (Fig. 1C). Buccal capsule total length to width ratio $0.47(0.44-0.50)$. Both parts circular in apical view, with smooth interior surface of walls (Fig. 1E,F). Apex of oesophagus surrounding posterior part of buccal capsule (Fig. 1C,F).

Oesophagus gradually widening from anterior end posteriorly, from 35 (25-36) at anterior end to 37 (37-40), then forming short dilatation 41 (41-42) wide just anterior to nerve ring (Fig. 1A). Nerve ring located at 159 (159163) from anterior end of body, surrounding constriction of oesophagus 37 (37-40) wide. Posterior to nerve ring, oesophagus gradually widening, bulbous at its posterior end, 63 (61-64) in diameter. Oesophagus length 393 (377-393), or $7.8 \%(6.9-8.0 \%)$ of body length.

Excretory glands and excretory pore not observed in studied specimens. Intestine thick-walled, narrow at oesophago-intestinal junction, then sharply widening posteriorly (Figs. 1A, 2B). In some specimens, anterior end of intestine wide, enveloping posterior end of oesophageal bulb. Rectum narrow, its walls slightly thicker at proximal end (Fig. 1G).
Genital system amphidelphic, typical of the genus. Vulva with slightly salient lips located at $2.43 \mathrm{~mm}(2.43-2.96 \mathrm{~mm})$ from anterior end; distance from anterior end to vulva occupying 48\% (48-54\%) of body length. Vagina short, lined with thin cuticle (Fig. 2C). Uteri joined, similar, thin-walled, filled with numerous eggs; most eggs containing fully developed embryos (Fig. 2A). Egg size 43-59 × 95-108 ( $=13)$. Both limbs of genital system U-bent at level of seminal receptacles, at 1,128 (908-1,270) from anterior end and at 698 (519-719) from posterior end. Proximal parts of both syngonia significantly overlapping level of vulva. Short testis zone observed closer to level of vulva in posterior syngonium and posterior to level of vulva in anterior one.

Tail gradually tapering from anus posteriorly, more abruptly tapering in posterior third (Fig. 1G). Tail end free from cuticular inflation, narrow, digitiform, with rounded tip. Tail length 297 (256-317), or 5.7\% (5.1-5.9\%) of body length. Phasmids poorly visible, located at 97 (67-97) from tail tip.

Type host: Banded rubber frog, Phrynomantis bifasciatus (Smith) (Amphibia: Anura: Microhylidae).

Site in host: Lungs.

Type locality: De Loskop, Limpopo Province, South Africa $\left(23^{\circ} 30^{\prime} \mathrm{S} ; 29^{\circ} 18^{\prime} \mathrm{E}\right)$.

Prevalence and intensity of infection: 5 out of $8(63 \%)$ hosts examined with the intensity of $9.6(2-18)$.

Type material: 5 specimens (holotype and 4 paratypes). Type specimens are stored in the helminthological collection of the Institute of Parasitology, Biology Centre, CAS, České Budějovice, Czech Republic; IPCAS N-1107.

Etymology: The species is named after Derek Engelbrecht (University of Limpopo) as a tribute to his help in specimen collection. 


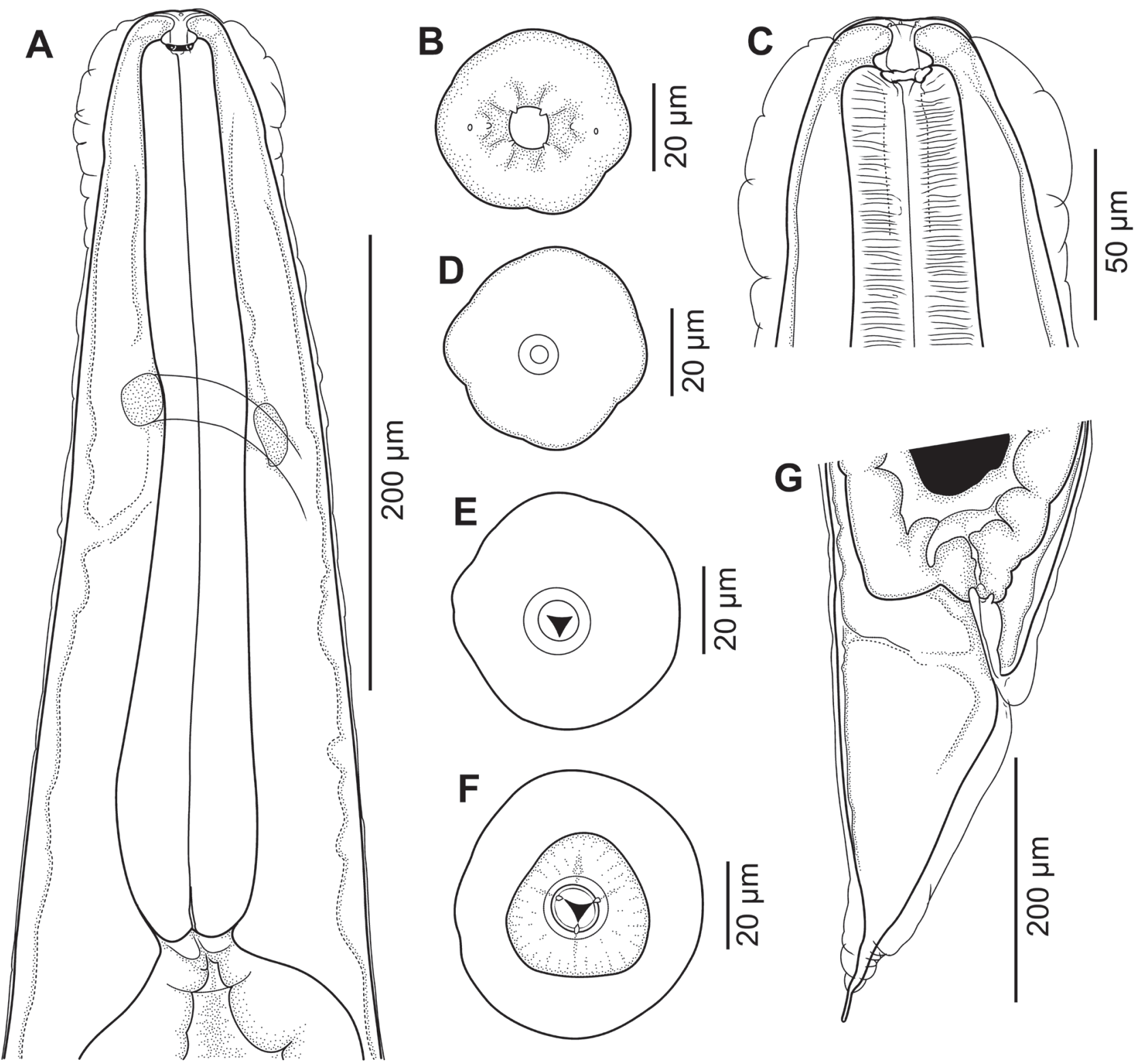

Fig. 1. Rhabdias engelbrechti sp. n. from Phrynomantis bifasciatus (Smith). A - anterior part of body, lateral view; B - anterior end, en face view; $\mathbf{C}$ - anterior end, lateral view; D - optical transverse section at level of vestibulum; $\mathbf{E}$ - optical transverse section at level of anterior part of buccal capsule; $\mathbf{F}$ - optical transverse section at level of posterior part of buccal capsule and apex of oesophagus; $\mathbf{G}$ - posterior part of body, lateral view. A, C, G - holotype; B, D-F - specimen from additional material.

Remarks. The new species is assigned to the genus Rhabdias based on its cuticle being inflated, more so at the anterior and posterior extremities, the presence of a small buccal capsule, the characteristic arrangement of its circumoral structures and parasitism in the lungs of amphibians.

Ten species of the genus were recorded as parasites of amphibians in the Afrotropical Realm (Junker et al. 2010; Tkach et al. 2014a): $R$. africanus, $R$. bdellophis, $R$. blommersiae, $R$. collaris, $R$. madagascariensis, $R$. ohlerae, $R$. picardiae, $R$. sylvestris, $R$. tanyai and $R$. vencesi.

Rhabdias engelbrechti sp. n. is close to $R$. africanus, $R$. blommersiae, $R$. madagascariensis, $R$. picardiae and $R$. vencesi in having a rounded anterior extremity, lacking distinct constrictions (in contrast to $R$. tanyai; see Junker et al. 2010) or dilatations (in contrast to R. collaris and
R. ohlerae; see Baker 1987, Junker et al. 2010), a comparatively small buccal capsule (in contrast to $R$. sylvestris; see Baker 1982, Tkach et al. 2014a) and in its specificity to an anuran host (in contrast to R. bdellophis parasitic in Apoda; see Baylis 1929).

Rhabdias engelbrechti differs from $R$. africanus parasitic in South African Bufonidae (Kuzmin 2001) in having a smaller body (3.8-6.1 $\mathrm{mm} v \mathrm{~s} 12.5-19.8 \mathrm{~mm}$ ), a smaller buccal capsule $(6-9 \mu \mathrm{m} \times 16-18 \mu \mathrm{m} v s \quad 15-20 \mu \mathrm{m} \times 20$ $23 \mu \mathrm{m}$ ), the mostly post-equatorial position of the vulva, the presence of cuticular inflation at the anterior extremity and the absence of lateral pseudolabia. Molecular differences between the two species were significant at $7.0 \%$ in the $12 \mathrm{~S}$ region (Table 2) and $10.6 \%$ in the coxl region (Table 3). Additionally, the two species also differed in 47 

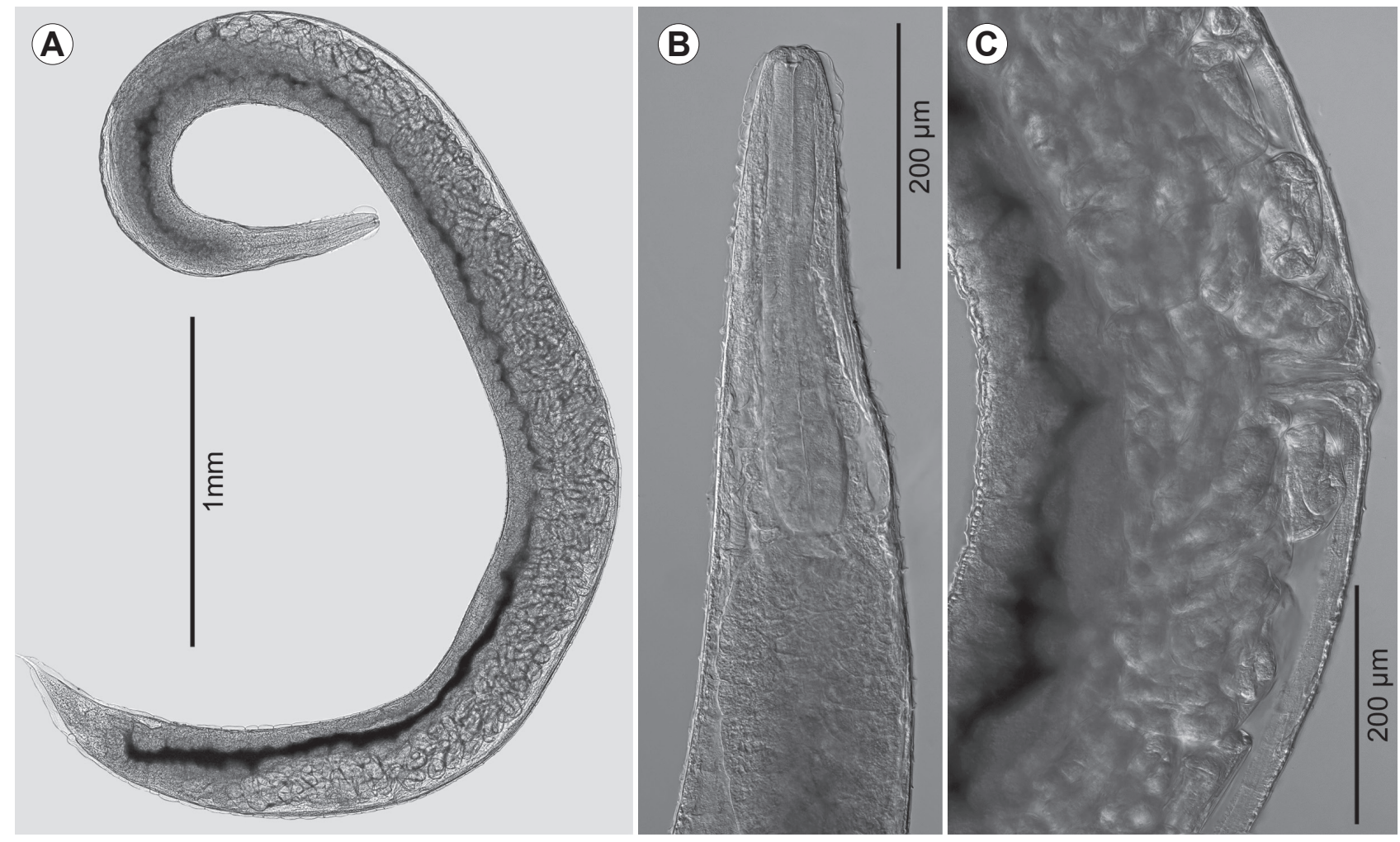

Fig. 2. Paratype of Rhabdias engelbrechti sp. n. from Phrynomantis bifasciatus (Smith). A - general view; B - anterior part of body, lateral view; $\mathbf{C}$ - region of vulva, lateral view.

out of $1,575(3.0 \%)$ nucleotide positions in the ITS $+28 \mathrm{~S}$ region (mostly in the ITS), which is a substantial level of divergence at species level (Tkach et al. 2006).

Rhabdias engelbrechti differs from $R$. blommersiae parasitic in Malagasy Mantellidae in its somewhat larger body size, when compared to the body length of $3.2-3.6 \mathrm{~mm}$ in the latter species (Kuzmin et al. 2013). In R. engelbrechti the lateral lips are smaller than the submedian ones, whereas in $R$. blommersiae all lips are of approximately equal size. The buccal capsule in the new species is wider than that in R. blommersiae (11-12 $\mu \mathrm{m}$ wide), and the distinct posterior part was not observed at all in the buccal capsule of the latter species. The vulva in $R$. blommersiae is pre-equatorial, whereas in $R$. engelbrechti it is mostly post-equatorial. Excretory glands were not observed in gravid specimens of $R$. engelbrechti, whereas they are apparent in R. blommersiae (see Kuzmin et al. 2013).

Rhabdias engelbrechti differs from $R$. madagascariensis parasitic in Malagasy Ranidae (Chabaud et al. 1961) in the absence of distinct excretory glands in gravid specimens, the presence of a globular cuticular inflation at the anterior extremity and a rounded, not truncated, anterior end. Body width near vulva in $R$. engelbrechti is $218-362 \mu \mathrm{m}$, whereas in the type specimen of $R$. madagascariensis the body is merely $150 \mu \mathrm{m}$ wide, though its body length $(3.5 \mathrm{~mm})$ is close to that in the smallest studied specimen of the new species $(3.8 \mathrm{~mm})$. A distinct rounded dilatation of the oesophagus just anterior to the nerve ring is absent in $R$. engelbrechti but present in $R$. madagascariensis, as seen on fig. 1C in Chabaud et al. (1961).
The new species is slightly smaller than $R$. picardiae from Bufonidae in South Africa, which is $8.0-8.4 \mathrm{~mm}$ long (Junker et al. 2010). Rhabdias picardiae lacks the distinct anterior spherical cuticular inflation typical of the new species. The buccal capsule in the new species is smaller than in $R$. picardiae (16-18 $\mu \mathrm{m}$ wide $v s$ 23-25 $\mu \mathrm{m}$ wide). The oesophagus in $R$. engelbrechti is shorter than in R. picardiae not only in absolute dimensions (293-393 $\mu \mathrm{m} v \mathrm{vs} 690$ $790 \mu \mathrm{m})$, but also in relation to body length $(8.6-9.9 \% v s$ 6.0-8.3\%). The DNA sequence divergence between the two species was lower in the more conserved $12 \mathrm{~S}$ gene ( $1.7 \%$ of differences; see Table 2 ), but much more substantial in the more variable cox 1 fragment $(8.4 \%$; see Table 3$)$.

Rhabdias engelbrechti differs from $R$. vencesi parasitic in Mantellidae on Madagascar (Junker et al. 2010) in having a smaller body (3.8-6.1 $\mathrm{mm} v s 9.3-13.2 \mathrm{~mm})$, narrower buccal capsule (16-18 $\mu \mathrm{m} v \mathrm{~s} 19-22 \mu \mathrm{m})$ and smaller eggs (95-108 $\mu \mathrm{m} \times 43-59 \mu \mathrm{m} v s$ 110-148 $\mu \mathrm{m} \times 56-72 \mu \mathrm{m})$. Besides, $R$. vencesi lacks the anterior cuticular swelling and the division of the buccal capsule into a distinct anterior and posterior part, characteristic of the new species. The oral opening is laterally elongated in $R$. vencesi while it is rounded in the new species. Sequence divergence between the two species was also significant with a $7.5 \%$ base pair difference in the $12 \mathrm{~S}$ gene (Table 2) and $9.9 \%$ in $\operatorname{cox} 1$ (Table 3).

The new species differs from $R$. tanyai described from Astylosternus rheophilus Amiet (Arthroleptidae) in Cameroon (Junker et al. 2010) not only in the shape of anterior extremity, as mentioned above, but also in the smaller size 
Table 2. Number (above diagonal) and percentage (below diagonal) of variable sites based on pairwise comparison within $360 \mathrm{bp}$ long alignment of partial sequences of $12 \mathrm{~S}$ gene of Rhabdias engelbrechti sp. $\mathrm{n}$. from Phrynomantis bifasciatus (Smith) and other published sequences of species of Rhabdias from Africa.

\begin{tabular}{lccccc}
\hline Species & $\begin{array}{c}\text { R. engelbrechtisp.n. } \\
\text { MG428408* }\end{array}$ & $\begin{array}{c}\text { R. africanus } \\
\text { MG428409* }\end{array}$ & $\begin{array}{c}\text { R. tanyai } \\
\text { FN434108* }\end{array}$ & $\begin{array}{c}\text { R. vencesi } \\
\text { FN434098* }\end{array}$ & $\begin{array}{c}\text { R. picardiae } \\
\text { FN434093* }\end{array}$ \\
\hline R. engelbrechti sp. n. & 0 & 25 & 19 & 27 & 6 \\
R. africanus & 7.0 & 0 & 30 & 22 & 24 \\
R. tanyai & 5.3 & 8.4 & 0 & 29 & 19 \\
$R$. vencesi & 7.5 & 6.2 & 8.1 & 0 & 25 \\
R. picardiae & 1.7 & 6.7 & 5.3 & 7.0 & 0 \\
\hline
\end{tabular}

* GenBank accession numbers.

Table 3. Number (above diagonal) and percentage (below diagonal) of variable sites based on pairwise comparison within 599 bp long alignment of partial sequences of coxl gene of Rhabdias engelbrechti sp. n. from Phrynomantis bifasciatus (Smith) and other published sequences of species of Rhabdias from Africa.

\begin{tabular}{lccccc}
\hline Species & $\begin{array}{c}\text { R. engelbrechti sp. n. } \\
\text { MG428410* }\end{array}$ & $\begin{array}{c}\text { R. africanus } \\
\text { MG428411* }\end{array}$ & $\begin{array}{c}\text { R. tanyai } \\
\text { FN434107* }\end{array}$ & $\begin{array}{c}\text { R. vencesi } \\
\text { FN434104* }\end{array}$ & $\begin{array}{c}\text { R. picardiae } \\
\text { FN434095* }\end{array}$ \\
\hline R. engelbrechti sp. n. & 0 & 63 & 66 & 59 & 50 \\
R. africanus & 10.6 & 0 & 74 & 72 & 72 \\
R. tanyai & 11.1 & 12.4 & 0 & 87 & 73 \\
$R$. vencesi & 9.9 & 12.1 & 14.6 & 0 & 56 \\
$R$. picardiae & 8.4 & 12.1 & 12.2 & 9.4 & 0 \\
\hline
\end{tabular}

* GenBank accession numbers.

of the body ( $>13.9 \mathrm{~mm}$ in $R$. tanyai) and the buccal capsule $(13 \mu \mathrm{m} \times 23 \mu \mathrm{m}$ in $R$. tanyai $)$. Sequence divergence between $R$. engelbrechti and $R$. tanyai was significant at $5.3 \%$ in the sequenced region of the $12 \mathrm{~S}$ gene and $11.1 \%$ in coxl (Tables 2, 3).

Phylogenetic analysis. The alignment of the sequenced regions of the nuclear ribosomal DNA (see Materials and Methods) included newly obtained sequences of $R$. engelbrechti sp. n. and $R$. africanus, as well as previously published sequences of other species of Rhabdias and the sequence of Pneumonema tiliquae as an outgroup. The alignment was $1,588 \mathrm{bp}$ long and required insertion of only a few gaps due to the overall high sequence similarity among ingroup taxa. Only 22 nucleotide positions had to be excluded from the analysis due to ambiguous homology. In the phylogenetic tree resulting from the Bayesian analysis, the new species formed a $100 \%$ supported clade with R. bufonis (Fig. 3). In turn, this clade clustered (100\% support) with the group of three species of Rhabdias parasitic in various amphibians in Asia, namely $R$. bermani Rausch, Rausch et Atrashkevich, 1984, R. bulbicauda Sarkar et Manna, 2004 and R. kongmongthaensis Kuzmin, Tkach et Vaughan, 2005. Another South African species, $R$. sylvestris, appeared on the tree as the taxon basal to the rest of the ingroup.

\section{DISCUSSION}

Rhabdias engelbrechti sp. n. lacks the pronounced morphological characters found in some species of Rhabdias parasitising Afrotropical anurans, such as the modification of the body wall in the anterior part observed in $R$. collaris, $R$. ohlerae (dilatation in both) and $R$. tanyai (constriction), or the presence of onchia and an enlarged buccal capsule found in R. sylvestris (Baker 1982, 1987, Junker et al.
2010). The buccal capsule morphology in $R$. engelbrechti is similar to that observed in $R$. picardiae, $R$. ohlerae and $R$. tanyai from Afrotropical anurans (Junker et al. 2010). In the latter three species the buccal capsule consists of a longer anterior part and shorter posterior part.

Rhabdias engelbrechti, R. picardiae and R. tanyai (all possessing divided buccal capsules) seem to be more similar to each other in the relatively conservative, non-coding $12 \mathrm{~S}$ gene sequences. Differences between the former three species were from $1.7 \%$ to $5.3 \%$, whereas each of them differed from $R$. africanus and $R$. vencesi (both lacking buccal capsule division) by $7.0-8.4 \%$ (Table 2 ). Further molecular phylogenetic studies including broader taxonomic diversity and additional genes, may provide data allowing for a better understanding of the origins of certain morphological features in this group of nematodes, including the structure of the buccal capsule.

Comparison of pairwise sequence variability between five species of Afrotropical species of Rhabdias demonstrated that cox 1 and $12 \mathrm{~S}$ genes show different levels of divergence among these nematode species (Tables 2, 3), which is fully expected considered the different levels of variation observed in these genes (Junker et al. 2010). However, the two genes have also indicated somewhat different levels of relatedness between compared taxa. For instance, sequences of $12 \mathrm{~S}$ genes suggested that $R$. tanyai and $R$. africanus were the most genetically distant species at $8.4 \%$ pairwise sequence difference while in the cox 1 gene $R$. tanyai and $R$. vencesi showed the highest level of divergence at $14.6 \%$. Comparison between other pairs of species (Tables 2, 3) shows additional inconsistencies in the results derived from the two genes. This raises a question regarding the phylogenetic signal and potential bias that may be introduced if these genes were used for broader phylogenetic analyses of the Rhabdiasidae. Currently 


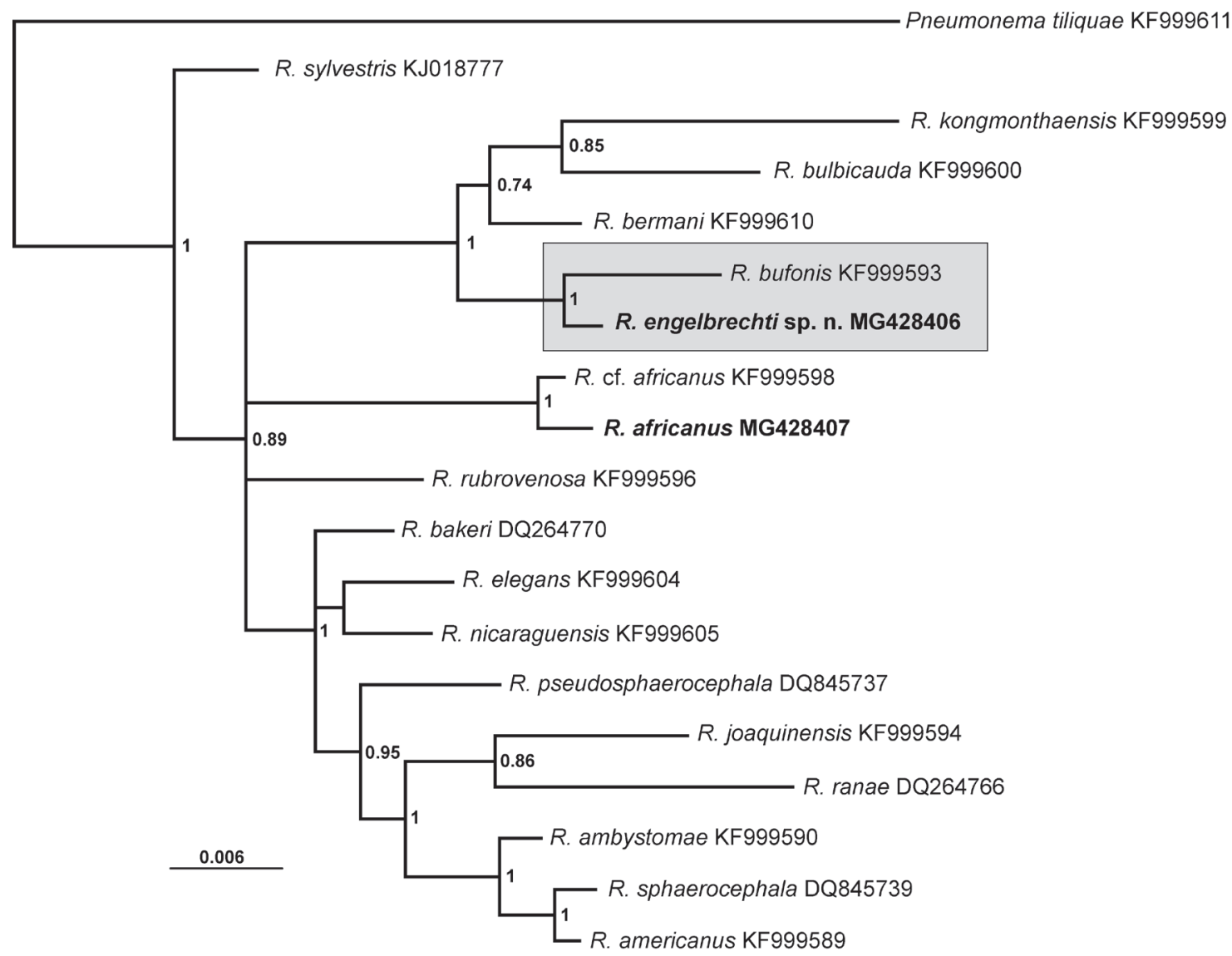

Fig. 3. Phylogenetic relationships among 17 taxa of Rhabdias, including R. engelbrechti sp. n. from Phrynomantis bifasciatus (Smith), resulting from Bayesian analysis (3,000,000 generations) based on sequences of the nuclear ribosomal DNA region sequences spanning the 3 ' end of $18 \mathrm{~S}$ rRNA gene, ITS region (ITS1+5.8S+ITS2) and 5' end of the $28 \mathrm{~S}$ rRNA gene. Posterior probabilities are shown at the internodes. New sequences in bold.

available sequence data do not allow for a more conclusive answer on this matter.

As expected, the phylogenetic tree obtained in our study is overall very similar to the trees recently published by Tkach et al. (2014a,b). Inclusion of the new and some additional species of Rhabdias in our tree compared to that published by Tkach et al. (2014a) outlined a strongly supported $(100 \%)$ group of five taxa which incorporates a $100 \%$ supported sub-clade of $R$. engelbrechti and $R$. bufonis. A highly conspicuous feature of this group of 5 taxa is that each of them parasitises a different family of amphibians. Moreover, R. bermani is a parasite of a caudatan, the Siberian newt Salamandrella keyserlingii Dybowski. From a geographic viewpoint, the taxa in this otherwise small clade are distributed from the Eastern Palearctic and Southeast Asia to the nearly southernmost part of the Afrotropical realm. This suggests that this clade is not only evolutionary quite ancient, but also conducive to easy host switching. The close, well supported relationship between $R$. engelbrechti from South Africa and R. bufonis distributed in the Palaearctic is particularly remarkable and somewhat unexpected. It suggests the existence of other, yet undescribed or merely not sequenced for ribosomal genes,
Afrotropical species of Rhabdias belonging to this clade. The huge geographic gap between the distribution areas of these two undoubtedly closely related species would be difficult to explain otherwise.

Of the four Afrotropical species of Rhabdias included in our phylogenetic analysis, only two, $R$. africanus and $R$. cf. africanus, turned out to be close relatives (Fig. 3). Based on molecular data, it is clear that the species previously provisionally identified as $R$. cf. africanus, in fact represents a new species awaiting formal description.

Denser geographic and taxonomic sampling of Rhabdias and inclusion of additional species in future phylogenetic analyses should allow to better resolve phylogenetic interrelationships not only among Afrotropical Rhabdias, but also their relationships with members of the genus from different continents.

Acknowledgements. This work is based on the research supported by the South African Research Chairs Initiative (SARChI) of the Department of Science and Technology and National Research Foundation of South Africa (Grant no. 101054). We are grateful to anonymous referees for the thorough revision and very useful suggestions that allowed to improve our manuscript. 


\section{REFERENCES}

BAKER M.R. 1982: Systematics and zoogeography of three new nematode parasites of the frog Breviceps sylvestris sylvestris FitzSimons from South Africa. Can. J. Zool. 60: 3134-3142.

BAKER M.R. 1987: Rhabdias collaris n. sp. (Nematoda: Rhabdiasidae) from frogs of Tanzania. Syst. Parasitol. 9: 199-201.

BAylis H.A. 1929: Some parasitic nematodes from the Uluguru and Usambara Mountains, Tanganyika Territory. Ann. Mag. Nat. Hist. 10: 372-381.

Casiraghi M., Bain O., Guerrero R., Martin C., Pocacqua V., Gardner S.L., Franceschi A., Bandi C. 2004: Mapping the presence of Wolbachia pipientis on the phylogeny of filarial nematodes: evidence for symbiont loss during evolution. Int. J. Parasitol. 34: 191-203.

Chabaud A.G., Brygoo E.R., Petter A. 1961: Déscription et caractères biologiques de deux nouveaux Rhabdias malgaches. Ann. Parasitol. Hum. Comp. 36: 752-763.

Huelsenbeck J.P., Ronquist F., Nielsen R., Bollback J.P. 2001: Bayesian inference of phylogeny and its impact on evolutionary biology. Science 294: 2310-2314.

Junker K., Lhermitte-Vallarino N., Barbuto M., Ineich I., WANJi S., BAIN O. 2010: New species of Rhabdias (Nematoda: Rhabdiasidae) from Afrotropical anurans, including molecular evidence and notes on biology. Folia Parasitol. 57: 47-61.

Kuzmin Y. I. 2001: Rhabdias africanus sp. nov. (Nematoda, Rhabdiasidae), a new nematode species from the South African toads (Amphibia, Bufonidae). Acta Parasitol. 46: 148-150.

Kuzmin Y., Du Preez L., Junker K., Bain O. 2013: A new species of Rhabdias Stiles et Hassall, 1905 (Nematoda: Rhabdiasi-

Received 17 September 2017

Accepted 7 November 2017 dae) from Blommersia domerguei (Guibé) (Amphibia: Mantellidae) in Madagascar. Folia Parasitol. 60: 469-474.

Kuzmin Y., Ткасн V.V. 2017: Rhabdias. World Wide Web electronic publication, http://izan.kiev.ua/ppages/rhabdias, 10/2017.

Posada D. 2008: jModelTest: Phylogenetic Model Averaging. Mol. Biol. Evol. 25: 1253-1256.

Rambaut A. 2012: Molecular evolution, phylogenetics and epidemiology: FigTree, http://ree.bio.ed.ac.uk/software/figtree/, $10 / 2017$

Tamura K., Stecher G., Peterson D., Filipski A., Kumar S. 2013: MEGA6: Molecular Evolutionary Genetics Analysis Version 6.0. Mol. Biol. Evol. 30: 2725-2729.

Tкасн V., Pawlowski J. 1999: A new method of DNA extraction from the ethanol-fixed parasitic worms. Acta Parasitol. 44: 147-148.

Tkach V.V., Halajian A., Kuzmin Y. 2014a: Phylogenetic affinities and systematic position of Entomelas sylvestris Baker, 1982 (Nematoda: Rhabdiasidae), a parasite of Breviceps sylvestris FitzSimons (Amphibia: Brevicipitidae) in South Africa. Syst. Parasitol. 87: 293-298.

Tкасн V.V., Kuzmin Y., Pulis E.E. 2006: Rhabdias bakeri sp. n. from lungs of wood frog, Rana sylvatica, in North America: the last sibling of Rhabdias ranae? J. Parasitol. 92: 631-636.

Tkach V.V., Kuzmin Y., Snyder S.D. 2014b: Molecular insight into systematics, host associations, life cycles and geographic distribution of the nematode family Rhabdiasidae. Int. J. Parasitol. 44: 273-284.

Cite this article as: Kuzmin Y., Halajian A., Tavakol S., Luus-Powell W.J., Tkach V.V. 2017: Description and phylogenetic position of a new species of Rhabdias Stiles et Hassall, 1905 (Nematoda: Rhabdiasidae) from the banded rubber frog, Phrynomantis bifasciatus (Smith) (Amphibia: Microhylidae), in South Africa. Folia Parasitol. 64: 035. 